\title{
A44 INVOLVEMENT OF CHEMOKINES IN THE SPONTANEOUS ANKYLOSIS MOUSE MODEL: FURTHER EVIDENCE FOR THE 'ENTHESEAL STRESS' HYPOTHESIS
}

K Braem, S Carter, C Deroose, F P Luyten, R J Lories Laboratory for Skeletal Development and Joint Disorders, Department of Musculoskeletal Sciences, Katholieke Universiteit Leuven, Leuven, Belgium

\subsection{6/ard.2010.129593f}

Background Studies in the spontaneous ankylosis model in ageing male DBA/1 mice and in patients with ankylosing spondylitis have provided evidence that inflammation and new tissue formation leading to joint or spine ankylosis are likely to be linked but are largely uncoupled processes. We have previously proposed the 'entheseal stress' hypothesis that defines microdamage to the enthesis as a starting point for these murine and human diseases.

Objectives To study the involvement of inflammatory pathways in the mouse model and link this to the activation of bone morphogenetic protein (BMP) signalling by cell stretching.

Methods Ageing male DBA/1 mice from different litters were caged together at the age of 8-10 weeks and studied for prospective signs of arthritis. Inflammation-associated gene expression was examined using RNA isolated from affected and healthy paws, as well as draining lymph nodes. DBA/1 mice were treated daily by injection of dexamethasone $(0.5 \mu \mathrm{g} / \mathrm{g}$ body weight). Severity of disease was assessed by histomorphology and by positron emission tomography (PET) using 18-deoxyfluoroglucose as a tracer. Bone loss in dexamethasone-treated or control mice was determined by in vivo dual-energy $\mathrm{x}$-ray absorptiometry. Chemokine expression was studied in vitro in mesenchymal cell types (primary synovial fibroblasts, periosteal and bone marrow stromal cells) by quantitative real-time PCR in the presence or absence of BMP2 and/or dexamethasone. C2C12 cells stably transfected with a BMP-reporter construct were used for cell stretch experiments in a dedicated bioreactor.

Results Gene expression arrays confirmed upregulation of specific BMPs in affected paws and a proinflammatory signature. Of interest, the changes appeared mainly local when compared 
with lymph node expression profiles. Dexamethasone treatment did not affect the incidence or severity of ankylosis, but was associated with a reduction in inflammatory changes in the paws at week 15 as measured by PET tracer uptake. Chemokines attracting neutrophils and lymphocytes were upregulated in affected paws. In vitro, BMP2 stimulation upregulated chemokines in different mesenchymal joint-associated cell types, but this effect was inhibited by dexamethasone. Cell stretch amplified BMP2 induced reporter activation.

Conclusion These experiments provide further evidence that entheseal stress, such as stretch, may contribute to activation of BMP signalling in the enthesis, triggering both new tissue formation and an inflammatory phase. We therefore propose that anti-inflammatory strategies only inhibit the latter and not the former aspect. 